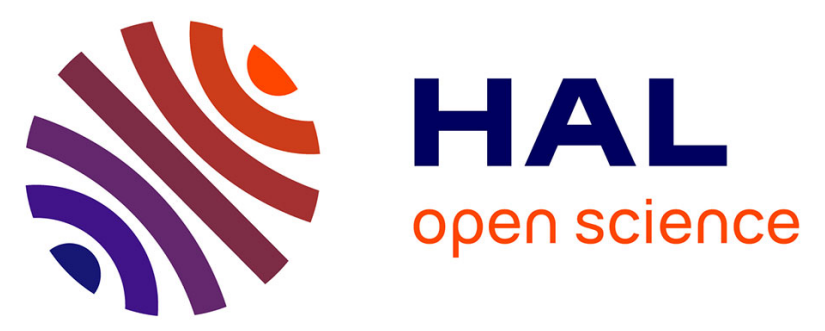

\title{
Effects of atom substitutions and dissolved carbonate species on monazite electrophoretic mobility
}

\author{
Anthony Geneyton, L. O. Filippov, Nour-Eddine Menad
}

\section{To cite this version:}

Anthony Geneyton, L. O. Filippov, Nour-Eddine Menad. Effects of atom substitutions and dissolved carbonate species on monazite electrophoretic mobility. Colloids and Surfaces A: Physicochemical and Engineering Aspects, 2019, 570, pp.141-146. 10.1016/j.colsurfa.2019.03.005 . hal-02380712

\section{HAL Id: hal-02380712 \\ https://hal.science/hal-02380712}

Submitted on 22 Oct 2021

HAL is a multi-disciplinary open access archive for the deposit and dissemination of scientific research documents, whether they are published or not. The documents may come from teaching and research institutions in France or abroad, or from public or private research centers.
L'archive ouverte pluridisciplinaire $\mathbf{H A L}$, est destinée au dépôt et à la diffusion de documents scientifiques de niveau recherche, publiés ou non, émanant des établissements d'enseignement et de recherche français ou étrangers, des laboratoires publics ou privés.

\section{다)(1) $(5$}

Distributed under a Creative Commons Attribution - NonCommercial| 4.0 International 


\title{
Effects of atom substitutions and dissolved carbonate species
}

\section{on monazite electrophoretic mobility}

\author{
A. Geneyton ${ }^{\text {a,b }}$, L.O. Filippov a,*, N.-E Menad ${ }^{\text {b }}$ \\ ${ }^{\text {a }}$ Université de Lorraine, CNRS, GeoRessources, F- 54000 Nancy, France \\ b BRGM, Water, Environment and Ecotechnologies Division, Waste and Raw Materials \& \\ Recycling Unit, 3 Avenue Claude Guillemin, BP 36009, 45060 Orléans Cedex, France
}

*Corresponding author: lev.filippov@univ-lorraine.fr, +33 37274 45 46, 2 rue du Doyen Marcel Roubault, 54500, Vandoeuvre Les Nancy

\section{GRAPHICAL ABSTRACT}

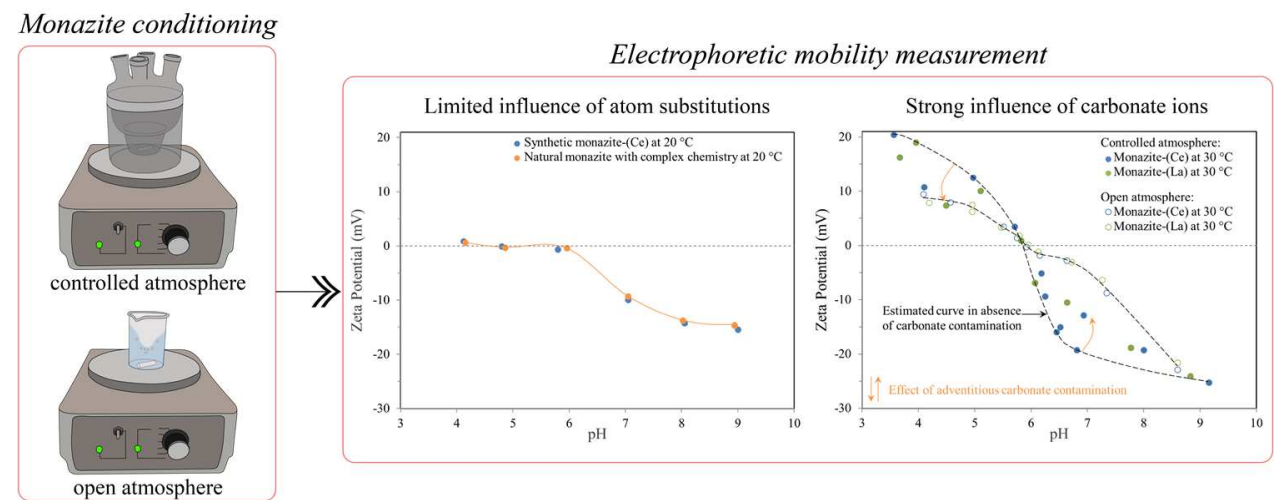

Note: Black and white should be used for any figures in print 


\begin{abstract}
In this study, the atom substitutions that commonly affect the monazite lattice were considered as potential factors affecting the monazite electrophoretic mobility. The influence of light rare-earth elements (LREE) substitutions and the presence of thorium, calcium, and silicate within the monazite crystal lattice was also examined using a natural monazite and synthetic cerium, lanthanum and neodymium monazite materials. Electrophoretic mobility measurements performed after treatment in an electrolyte solution equilibrated with air outline that LREE substitutions and other substitutions observed in the tested natural monazite did not affect the mineral surface properties.
\end{abstract}

Conversely, the electrophoretic mobility of the synthetic monazites was found to be significantly affected by the amount of dissolved carbonate species present in the aqueous media. More precisely, carbonate species were found to decrease the electrophoretic mobility of monazite. Unlike tests performed with a solution equilibrated with air, the electrophoretic mobility of monazite treated in a $\mathrm{CO}_{2}$ depleted electrolyte solution, under controlled atmosphere, were found erratic. This highlights the difficulty in obtaining reliable electrophoretic mobility data when the carbonate content in the supporting electrolyte solutions is not controlled.

KEYWORDS: Rare-earth minerals, Lanthanides, Monazite, Electrophoretic mobility, Zeta potential, Substitution, $\mathrm{CO}_{2}$, carbonate
Abbreviations:
LREE: Light rare-earth elements,
IEP: Iso-electric point,

PZC: Point of zero charge, XRD: X-ray diffraction, EDL: Electrical double layer 


\section{Introduction}

Electrophoretic mobility and potentiometric titration are two crucial techniques to study mineral surface properties. Significant discrepancies in the IEPs and the PZCs of monazite and other rare-earth semi-soluble salts minerals were found in the literature [1-3]. In the case of monazite, published IEPs range mainly from 5 to 6.5, although IEPs outside this range are also reported (see Table 1). Beyond variations in apparatuses and analytical protocols, different explanations, listed below, were proposed to explain such variability in the monazite surface properties.

A common explanation is that the atom substitutions that commonly affect the monazite lattice result in the exposure of the substituting atoms or point defects on the mineral surface changing its properties $[4,5]$. This phenomenon has already been described for certain minerals, such as cassiterite or ilmenite [6,7]. In the case of monazite, different types of elements may be naturally incorporated in the monazite lattice. Although cerium, lanthanum, praseodymium and neodymium are generally predominant, heavier rare-earth elements may be present in significant amounts in the monazite chemical composition [8]. To a certain extent, trivalent lanthanides may be directly substituted by tetravalent actinides forming lattice vacancies [9]. Coupled substitutions of trivalent lanthanides by divalent elements, notably calcium, and tetravalent elements are also reported and explains the observed incorporation of up to $31.5 \mathrm{wt} \%$ of $\mathrm{ThO}_{2}$ and $15.6 \mathrm{wt} \%$ of $\mathrm{UO}_{2}$ in the monazite lattice [9-11]. Furthermore, coupled substitution of LREE and phosphate by actinides and silicate may occur and explain the frequent presence of silicon in monazite chemical composition [12]. LREE may also be directly substituted by alkaline earth metals, notably calcium and strontium, leading to oxygen vacancies [9].

Monazite surface properties are also suggested as being significantly affected by the crystal defects caused by the radioactive decay chain of the radiogenic actinides isotopes naturally present within the monazite lattice [13]. This assumption is based on the fact that the radioactive decay chains of actinides elements, such as thorium, release recoil nuclei, and the induced 
collision cascades are known to generate intense atom displacements, which may ultimately induce an amorphisation $[14,15]$. However, in the case of monazite, the influence of crystal lattice defects on zeta potential is likely to be limited, since generally only isolated defects are observed [16,17]. A recent study highlights that despite exposure to high doses of radiation, a crystalline state is maintained due to the electronic energy loss of released alpha particles that heal monazite lattice defects [18].

It cannot be excluded that variability in published IEPs is induced by the presence of mineral inclusions in monazite crystal, or the presence of middling grains and non-monazite grains in analysed materials. Indeed, large and pure monazite specimens are scarce and electrophoretic mobility measurements are frequently performed on monazite samples concentrated from heavy minerals sands (see Table 1).

In aqueous media, free lanthanide ions are known to have a strong affinity for dissolved carbonate species [19]. In a previous study, we examined the affinity of monazite surface lanthanide ions with carbonate species using synthetic monazites. It was shown that treatment with significant amounts of sodium carbonate did not result in mineral surface carbonation after thorough rinsing with deionised water [20]. However, in the literature, the monazite electrophoretic mobility has been reported tending towards zero, for a broad $\mathrm{pH}$ range, when measured in a $\mathrm{Na}_{2} \mathrm{CO}_{3}$ solution rather than $\mathrm{NaCl}$ solution [21]. This may suggest that the monazite surface ions react with dissolved carbonate species, although this interaction is not strong enough to result in detectable surface carbonation after thorough rinsing. This interaction may explain the variability observed in published IEP values and suggest that the aqueous media temperature that controls the solubility of carbon dioxide [22], and thus the concentration of carbonate species in the bulk, affect the monazite electrophoretic mobility. 


\begin{tabular}{cll}
\hline \multicolumn{1}{c}{ V } & Monazite origin & References \\
alue & & \\
\hline 3. & Korea (H.S.) & Choi et Whang, 1963 [23] \\
5 & &
\end{tabular}

4.

7

China $\quad$ Ren et al., 2000 [24]

5 Bayan Obo, China (CB) Luo \& Xiangyong, 1987 [25]

$5 \quad$ Namibia (CB) $\quad$ Espiritu \& Waters, 2018 [26]

5. São Gonçalo do Sapucai,

$2 \quad$ Brazil

Pavez et al., 1996 [27]

5.
Australia (H.S.)
Cheng et al., 1993 [28]

3

5.

New Mexico, USA

Nduwa-Mushidi \& Anderson, 2017

3

[13]

5.

3

China

Zhang \& Honaker, 2018 [29]

5.

Bayan Obo, China (CB) Li et al., 2018 [30]

4

5.

Near Rosetta, Egypt

Abeidu, 1972 [31]

5

5.

Brazil

Azizi et al.,2016 [32]

9

5.

Itambé, Brazil

Sarvaramini et al., 2016 [33]

9

6 Hebei, China

Zhang \& Honaker, 2017 [34]

6.

China

Zhang et al., 2017 [35]

5

6. Not indicated

Abaka-wood et al., 2017 [36] 
Note: H.S. = heavy mineral sands; $\mathrm{CB}=$ carbonatite

The aim of this study is to investigate the effect of atom substitutions on the monazite electrophoretic mobility. To this end, a comparative study of the electrophoretic mobility of a natural monazite with a complex composition and some synthetic monazite materials with various chemical compositions was performed. The natural presence of dissolved carbonate species during the treatment of monazite was also considered as a factor affecting electrophoretic mobility. 


\section{Materials and methods}

\subsection{Monazite samples}

A monazite powder was prepared using a monocrystal from Manangotry (Madagascar). Further information on the sample origin, crystal size reduction, and impurities removal is detailed by Richard et al. (2015), who analysed and prepared this sample [38]. Based on 32 electron microprobe analyses, they showed that the composition of this monazite powder was highly homogeneous. A typical electron microprobe analysis is presented in Table 2.

Table 2: Electron microprobe analysis of the monazite monocrystal expressed in weight percent and reproduced from Richard et al. (2015) [38]

\begin{tabular}{|c|c|c|c|c|c|c|c|c|c|c|c|c|c|c|c|}
\hline osition (wt \%) & $\mathrm{P}_{2} \mathrm{O}_{5}$ & $\mathrm{SiO}_{2}$ & $\mathrm{Ce}_{2} \mathrm{O}_{3}$ & $\mathrm{La}_{2} \mathrm{O}_{3}$ & $\mathrm{Nd}_{2} \mathrm{O}_{3}$ & $\mathrm{Pr}_{2} \mathrm{O}_{3}$ & $\mathrm{Sm}_{2} \mathrm{O}_{3}$ & $\mathrm{Gd}_{2} \mathrm{O}_{3}$ & $\mathrm{Dy}_{2} \mathrm{O}_{3}$ & $\mathrm{CaO}$ & $\mathrm{Y}_{2} \mathrm{O}_{3}$ & $\mathrm{ThO}_{2}$ & $\mathrm{UO}_{2}$ & $\mathrm{PbO}$ & Total \\
\hline Average & 26.58 & 1.99 & 28.31 & 13.76 & 9.78 & 2.91 & 1.05 & 0.43 & 0.04 & 0.95 & 0.12 & 12.93 & 0.28 & 0.31 & 99.44 \\
\hline Standard deviation & 0.30 & 0.13 & 0.48 & 0.41 & 0.39 & 0.35 & 0.28 & 0.27 & 0.08 & 0.08 & 0.07 & 0.75 & 0.09 & 0.17 & - \\
\hline
\end{tabular}

Pure cerium, lanthanum and neodymium monazite materials were the three synthetic materials studied. Cerium, lanthanum and neodymium monazite precursors were obtained through a two-step chemical synthesis. Lanthanide nitrates with the formula $\mathrm{Ln}\left(\mathrm{NO}_{3}\right)_{3} .6 \mathrm{H}_{2} \mathrm{O}$ ( $\mathrm{Ln}$ : lanthanides) and USP grade phosphoric acid were used for the monazite precursors synthesis. Cerium nitrate (99 wt\% purity) and neodymium nitrate (99.9 wt\% purity) were supplied by Sigma Aldrich, lanthanum nitrate (99.9 wt\% purity) was supplied by Merck. A diluted $\mathrm{H}_{3} \mathrm{PO}_{4}$ solution $\left(55 \mathrm{wt} \% \mathrm{H}_{3} \mathrm{PO}_{4}\right)$ was heated to $90-95{ }^{\circ} \mathrm{C}$, and rare-earth nitrates were added at a weight ratio of 1 to 4 (rare-earth nitrates to diluted phosphoric acid). Once complete dissolution was achieved, which takes a few seconds, the solution was quenched in a large volume of boiling deionised water $(18 \mathrm{M} \Omega \mathrm{cm})$ resulting in fast precipitation of lanthanide orthophosphates with rhabdophane structure. The suspension was removed from the heat, stirred for 30 minutes, and filtered. The filtrate was then rinsed several times and dried.

In a study which will later be the subject of a dedicated paper, we highlighted that the 
rhabdophane-to-monazite thermal conversion is a three steps process. First dehydration of the rhabdophane structure occur below $300{ }^{\circ} \mathrm{C}$, then a transitional monazite structure is obtained at around $600{ }^{\circ} \mathrm{C}$, and finally, recrystallisation of the monazite occurs at around $1100{ }^{\circ} \mathrm{C}$. In order to ensure total conversion of hydrated orthophosphates with a rhabdophane structure into dehydrated orthophosphates with a monazite structure, the dried precipitates were successively heated at $350{ }^{\circ} \mathrm{C}, 850{ }^{\circ} \mathrm{C}$, and $1250{ }^{\circ} \mathrm{C}$ for $20 \mathrm{~min}$ at each temperature. This thermal treatment was performed in an electric muffle furnace using glassy carbon crucibles. The XRD diffractograms presented in Figure 1 confirmed that the thermal treatment led to the monazite structure. Further details on the synthesis of rhabdophane materials and further explanations on the selected thermal conversion route will be given in a dedicated paper.

In order to perform electrophoretic mobility measurements, the natural and synthetic monazites were pulverised in an agate planetary ball mill (Fritsch Pulverisette) for 30 minutes.

\section{2. $X$-ray diffraction $(X R D)$}

The synthetic monazites were analysed at the LIEC laboratory using a Bruker D8-Advance diffractometer equipped with a cobalt anticathode $(35 \mathrm{kV}-45 \mathrm{~mA})$ as an X-ray emitting source $(\lambda=1.78897 \AA$ ), $\theta-2 \theta$ goniometer, and LynxEye energy-dispersive one-dimensional detector. XRD analyses were performed with a $2 \theta$ angle ranging from $3^{\circ}$ to $64^{\circ}$, a step size of $0.034^{\circ}$ and an acquisition time of 3 seconds. The synthetic materials were identified by comparing their XRD patterns to standard line patterns available from the "Powder Diffraction File 2000" database. 


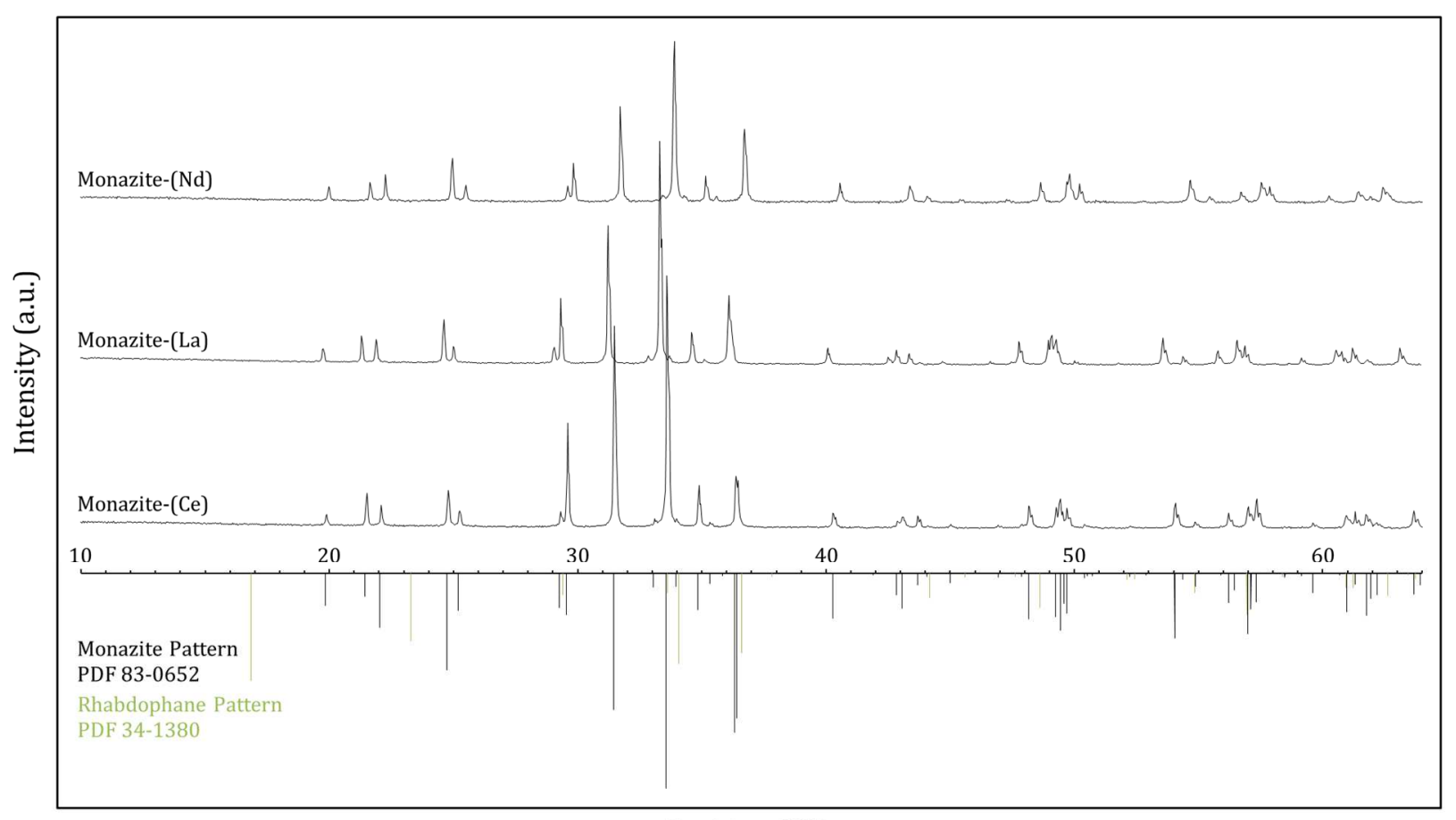

Position (20)

Figure 1: X-ray diffractograms of the synthetic monazite materials

( 2 columns fitting figure)

\subsection{Electrophoretic mobility measurement and zeta potential calculation}

Electrophoretic mobility measurements were performed using a ZetaCompact zetameter from CAD Instruments. With this device, particles are illuminated by a laser sheet and their electrophoresis directly observed by camera. This direct observation allowed fine control of the absence of settling particles. A distribution of the particle electrophoretic mobility was obtained, and the Smoluchowski equation was used to calculate a zeta potential distribution [39]. Prior to any series of measurements, the electrodes conductivity was controlled with a solution of $1 \times 10^{-2} \mathrm{~mol} \mathrm{~L}^{-1} \mathrm{KCl}$, and the stationary layer setting was controlled with a standard suspension of $\mathrm{TiO}_{2}$ whose zeta potential must be in the range of $-30 \mathrm{mV}$ to $-40 \mathrm{mV}$.

In order to see the effect of dissolved carbonate species on the monazite electrophoretic mobility, two distinct treatment protocols were followed. With the first protocol, the electrolyte solution was generated with deionised water $(18 \mathrm{M} \Omega \mathrm{cm})$ equilibrated with air by shaking, using 
a mechanical shaker. This equilibrium was achieved at variable room temperature $\left(20{ }^{\circ} \mathrm{C}\right.$ or $\left.30{ }^{\circ} \mathrm{C}\right)$. The monazite treatment was performed in an open beaker at the same room temperature. With the second protocol, the electrolyte solution was generated with deionised water boiled for two hours to decrease the amount of dissolved carbonate species. After the addition of potassium chloride, the electrolyte solution was placed for cooling inside individual sealed vessels. The monazite samples were treated in a closed glass reactor equipped with five inlets in which a $\mathrm{pH}$ probe, an air tube, syringes (containing $\mathrm{KOH}$ and $\mathrm{HCl}$ solutions), and a sampling pipe connected to the zetameter were hermetically inserted (see Figure 2). After pouring the deionised water, the air inside the reactor was flushed with pure dinitrogen, and then a dinitrogen overpressure (circa $15 \mathrm{mmHg}$ ) was applied to limit exchanges with the atmosphere and consequent $\mathrm{CO}_{2}$ contaminations. The same procedure was followed to insert the monazite material.

These two treatment protocols shared common steps. $60 \mathrm{~mL}$ of the solution of deionised water containing $10^{-3} \mathrm{~mol} \mathrm{~L}^{-1} \mathrm{KCl}$ as supporting electrolyte was $\mathrm{pH}$ adjusted with hydrochloric acid or potassium hydroxide solutions produced with $\mathrm{CO}_{2}$-depleted or air-equilibrated deionised water. $24 \mathrm{mg}$ of milled monazite was added in the reactor, and the suspension was stirred for 10 minutes under continuous $\mathrm{pH}$ adjustment. The mineral suspension was then pumped into the zetameter located in a second room whose temperature was maintained at $20^{\circ} \mathrm{C}$. It is thus important to differentiate the variable treatment temperature and the fixed measurement temperature of $20{ }^{\circ} \mathrm{C}$. A delay of 10 minutes was required for settling coarse particles inside the zetameter measuring cell and detecting solely fine particles whose motion was Brownian in nature. A population of between 500 and 1500 particles on the stationary layer was typically observed after coarse particles settling. For each $\mathrm{pH}$ condition, measurements were repeated five times. Calculated standard deviations typically ranged from 0.1 to $0.3 \mathrm{mV}$ and did not exceed $0.5 \mathrm{mV}$. 


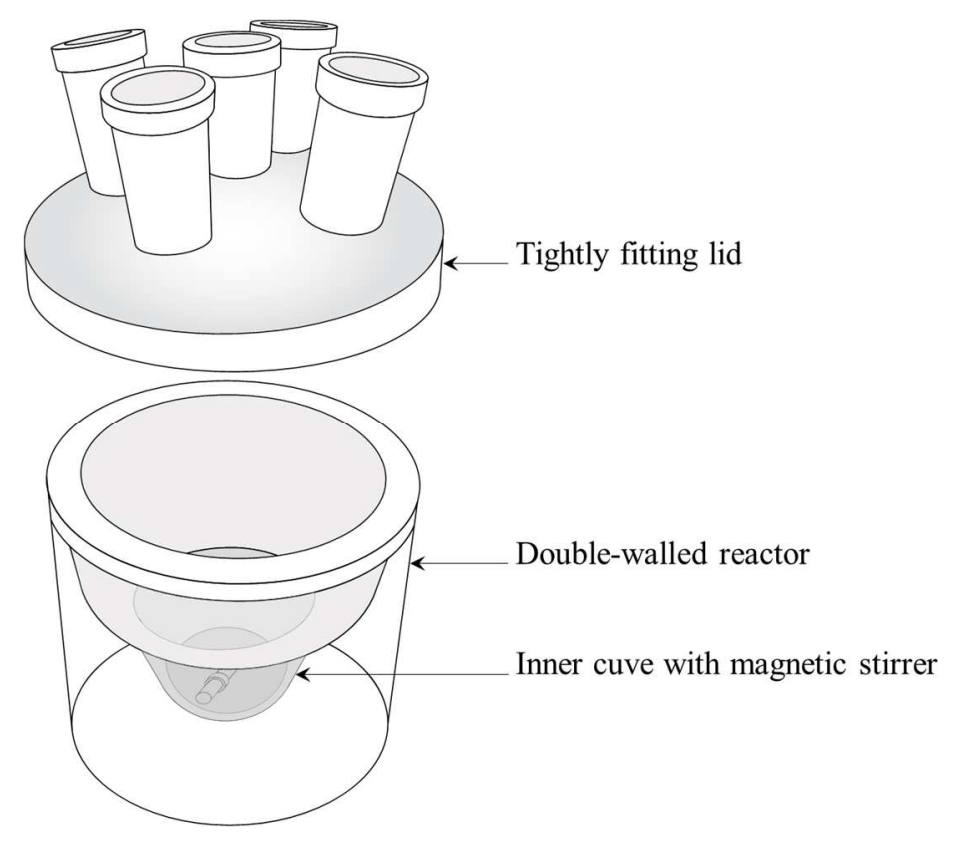

Figure 2: Schematic drawing of the glass reactor used in this study

( 1 column fitting figure)

\section{Results and discussion}

\subsection{Zeta potential of monazite treated in an electrolyte solution equilibrated with air}

As discussed in the introduction, it is suspected that dissolved carbonate species influence the monazite electrophoretic mobility. Therefore, in the case of monazite, the temperature that affects the carbon dioxide solubility and thus the carbonate species concentration in the bulk may be a determining parameter of zeta potential. A slight increase of the temperature of the electrolyte solutions may indeed significantly decrease the carbon dioxide solubility [22]. Therefore, in order to see the influence of LREE substitutions and the treatment temperature, the synthetic monazites were treated at a room temperature of $20{ }^{\circ} \mathrm{C}$ and $30{ }^{\circ} \mathrm{C}$ and in the $\mathrm{pH}$ range of 4 to 9 using an electrolyte solution equilibrated with the atmosphere. The obtained zeta potential values reported in Figure 3 outline the influence of the treatment temperature. Indeed, the zeta potential of the synthetic cerium monazite treated at $20{ }^{\circ} \mathrm{C}$ was found closer to $0 \mathrm{mV}$ than when treated at a higher temperature. Since the zeta potential of the standard $\mathrm{TiO}_{2}$ suspension was unchanged and the temperature of each cerium monazite suspensions was stabilized at $20{ }^{\circ} \mathrm{C}$ after the settling 
period inside the zetameter, those zeta potential differences may be explained only by a difference in the treatment temperature, and thus a possible difference in the amount of dissolved carbonate species.

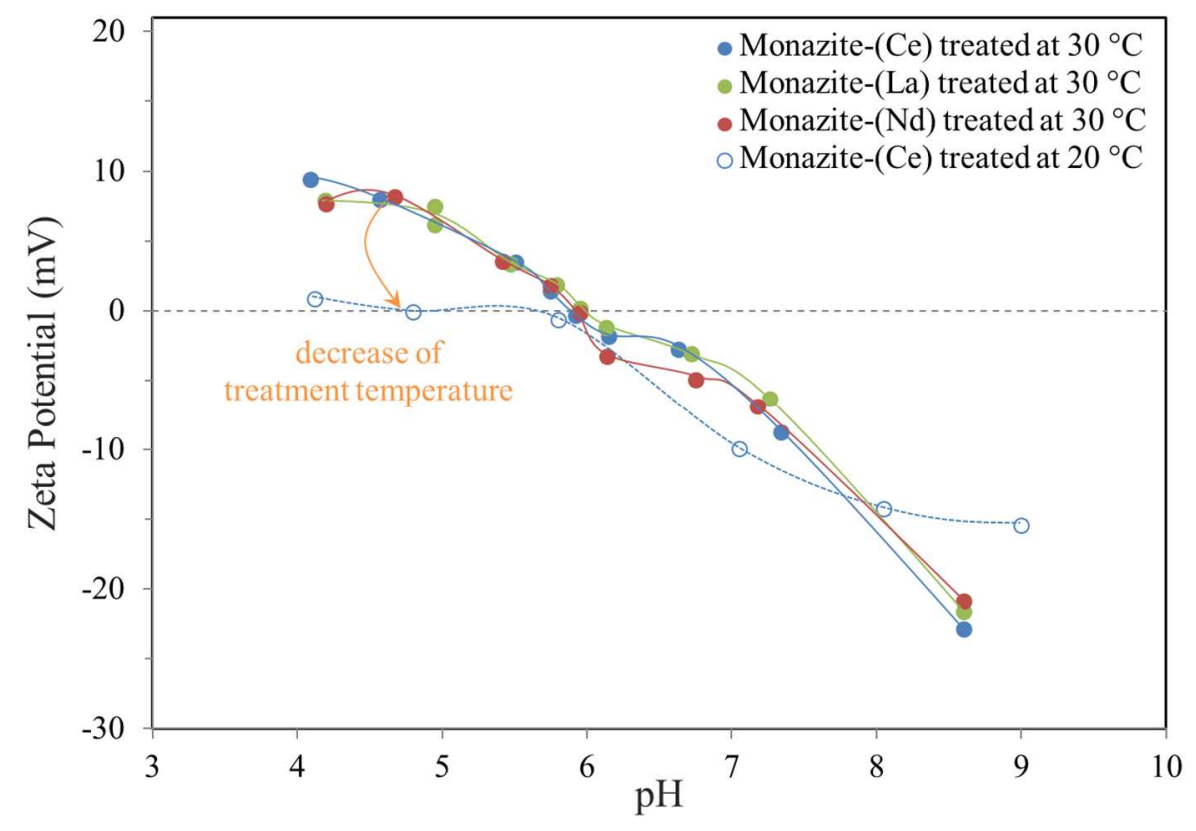

Figure 3: Effect of the chemical composition of synthetic monazites and treatment temperature on the evolution of zeta potential as a function of $\mathrm{pH}$ in an electrolyte solution equilibrated with air

\section{(1.5 columns fitting figure)}

The data presented in Figure 3 also highlight that when using electrolyte solutions equilibrated with air, the electrophoretic mobilities of the synthetic monazites are identical. The IEP of the three synthetic monazites treated at $30^{\circ} \mathrm{C}$ was observed at $\mathrm{pH}$ 5.9. These results suggest that LREE substitutions will not affect the monazite surface properties. In order to see the effect of the other atom substitutions that may occur in the monazite lattice, the electrophoretic mobility of the cerium monazite material was compared to that of a natural monazite sample with a complex chemical composition. For this comparison, an electrolyte solution equilibrated with air was used, and both monazite treatment and measurement were performed at a temperature of $20{ }^{\circ} \mathrm{C}$. As depicted in Figure 4, the electrophoretic mobility of monazite was found to be unaffected by the presence of substituting atoms such as thorium, contrary to what was suggested in the literature. 


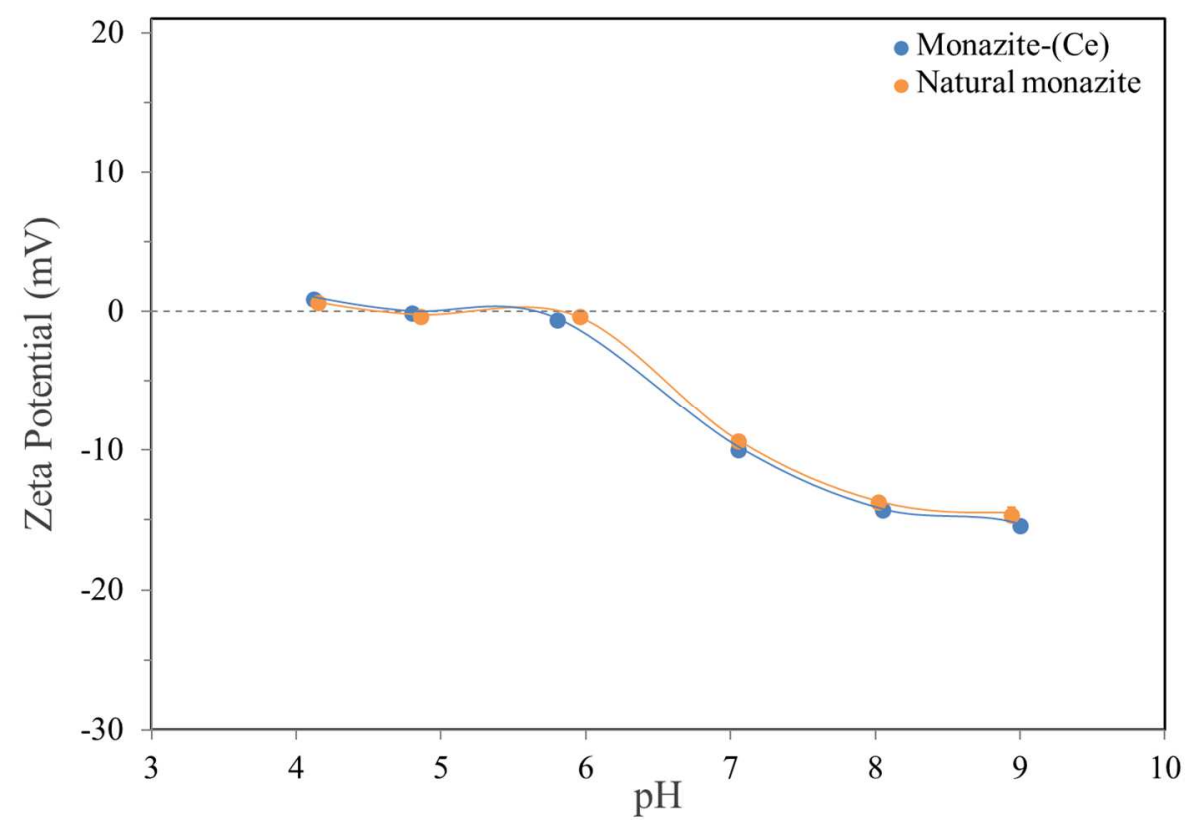

Figure 4: Effect of the complex chemical composition of the natural monazite on the evolution of zeta potential as a function of $\mathrm{pH}$ in an electrolyte solution equilibrated with air and at a room temperature of $20{ }^{\circ} \mathrm{C}$

\section{(1.5 columns fitting figure)}

\subsection{Zeta potential of monazite treated in $\mathrm{CO}_{2}$ depleted electrolyte solution}

In order to confirm the influence of dissolved carbonate species on the monazite electrophoretic mobility, the synthetic cerium and lanthanum monazites were treated at $30{ }^{\circ} \mathrm{C}$, in a controlled atmosphere, using a $\mathrm{CO}_{2}$ depleted electrolyte solution. The obtained zeta potential values are presented in Figure 5. From a general perspective, although erratic zeta potential values were observed, it seems that the presence of lower amounts of dissolved carbonate species led to higher electrophoretic mobilities. Certain zeta potential values obtained when treating monazite under controlled atmosphere are similar to the ones obtained when the electrolyte solutions were equilibrated with air. Therefore, we assume that the inconsistency of the zeta potential values was caused by carbon dioxide contamination. A trendline of the expected zeta potential in absence of carbon dioxide contamination may be drawn, pointing out the shifting of zeta potential towards the values observed when treating monazite in open atmosphere, and thus in the presence of larger amounts of dissolved carbonate species. Interestingly, this trendline 
reveals an IEP similar to the one obtained when the electrolyte solutions were equilibrated with air.

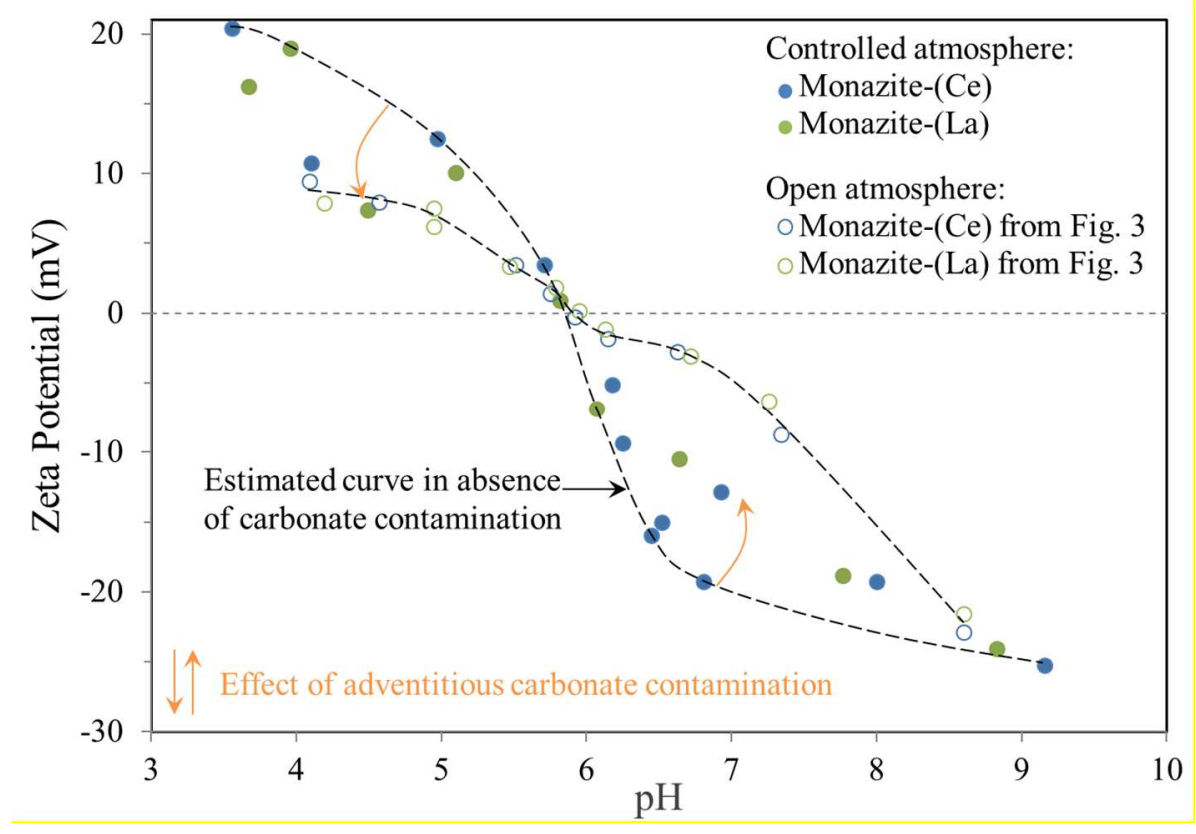

Figure 5: Effect of the exchanges with the atmosphere during the treatment on the evolution of zeta potential of synthetic monazite as a function of $\mathrm{pH}$ and at a room temperature of $30{ }^{\circ} \mathrm{C}$

\section{(1.5 columns fitting figure)}

For $\mathrm{pH}$ below the IEP, the treatment of monazite under open atmosphere rather than controlled atmosphere, and thus the presence of higher amounts of dissolved carbonate species in the electrolyte solution, decrease its zeta potential. This decrease may be attributed to chemical adsorption on surface lanthanide ions of bicarbonate ions, which are present in relatively low quantities in the bulk according to the speciation diagrams presented in Figure 6. This decrease may also be attributed to a concentration of bicarbonate ions in the EDL that compensates the positively charged monazite surface. However, at $\mathrm{pH}$ above the IEP, an increase in the amount of dissolved carbonate species induced higher zeta potential values, which is inconsistent with a simple presence of additional negative charges in the EDL or on the mineral surface. In a previous study, we suggested that the under-coordinated lanthanide ions on the monazite mineral surface may react with dissolved carbonate species [20]. However, in this study, as mentioned in 
the introduction section, after treatment with sodium carbonate and thorough rinsing with deionised water, surface probing did not highlight a significant carbonation, suggesting that the interactions between the monazite surface ions and dissolved carbonate species are not strong in nature. It may be proposed that at $\mathrm{pH}$ above the IEP, the presence of carbonate species on the mineral surface or within the EDL significantly affect the monazite surface properties or the EDL structure, resulting in a decrease of electrophoretic mobility. At around $\mathrm{pH} 9$, despite higher stability of dissolved carbonate species in aqueous media (see Figure 6), and thus higher kinetics of $\mathrm{CO}_{2}$ solubilisation, the influence of these species on the monazite electrophoretic mobility seems limited. Therefore, it is hard to conclude whether carbonate contamination becomes too significant or hydroxide ions become the major potential determining ions.
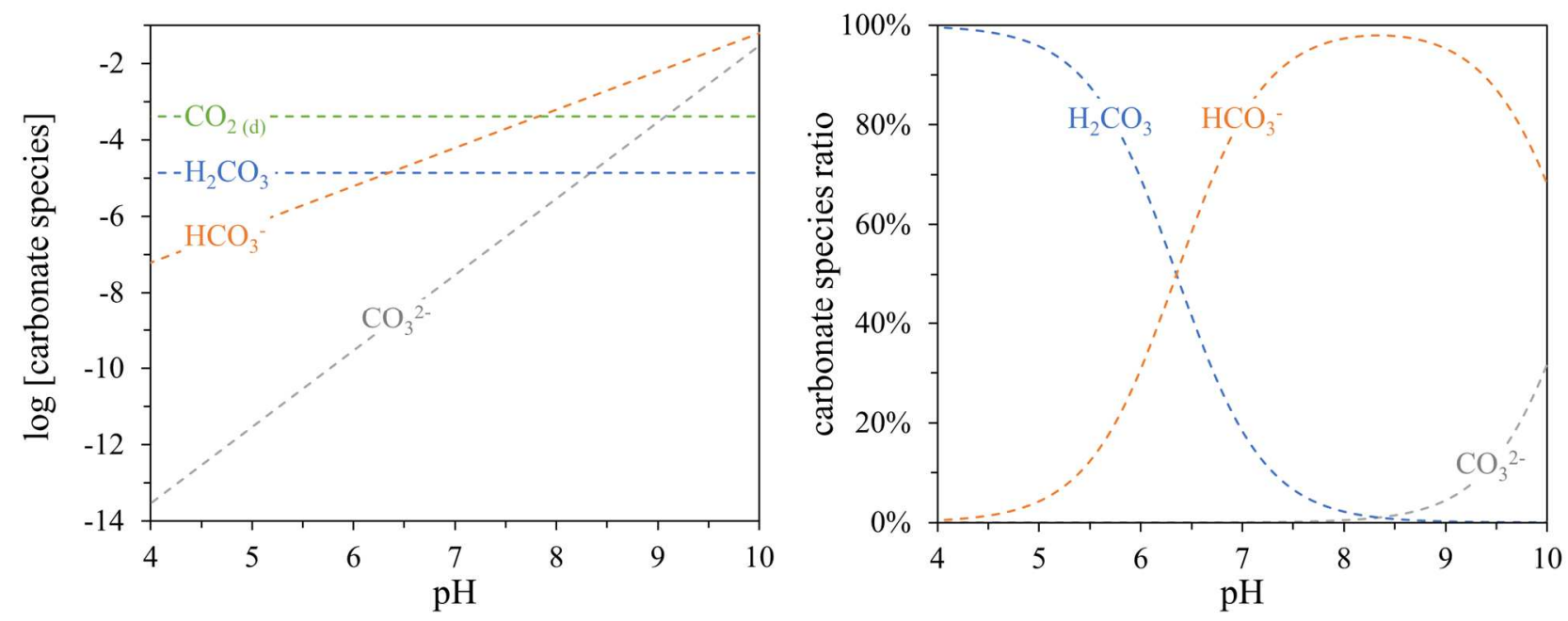

Figure 6: Carbonate species concentrations (left) and related speciation diagram (right) in the case of an aqueous solution equilibrated with the atmosphere

\section{( 2 columns fitting figure)}

To conclude on the effect of dissolved carbonate species, it was shown that when equilibrating the electrolyte solutions with air and controlling the room temperature, no erratic zeta potential values were observed. The compilation of all these results highlights that significant erraticness of zeta potential values appeared when attempting to decrease the amount of dissolved carbonate species without fine control of exchanges between the electrolyte solutions and the atmosphere. 
Hence, we recommend the use of a glove box and monitoring of dissolved $\mathrm{CO}_{2}$ to study the influence of carbonate species on the monazite zeta potential.

\section{Conclusions}

This study demonstrates the limited effects of the monazite chemical composition on its electrophoretic mobility. The electrophoretic mobilities of synthetic cerium, lanthanum and neodymium monazite materials and of a natural monazite sample which present a complex chemical composition were found identical when measured in electrolyte solutions equilibrated with air.

Conversely, it was shown that dissolved carbonate species have a strong influence on the monazite electrophoretic mobility. Indeed, the monazite treatment protocol (controlled and open atmosphere) and the temperature of the electrolyte solution during this treatment significantly affect the monazite electrophoretic mobility. The results underscore that carbonate species reduce the monazite electrophoretic mobility. The decrease of electrophoretic mobility at $\mathrm{pH}$ above the IEP may not be easily explained and suggests that the influence of dissolved carbonate species on the monazite surface properties or on the EDL structure is complex.

Electrophoretic mobility measurement is a common method to determine the zeta potential of a mineral and to study the phenomena that occur on the mineral surface, such as the adsorption of surfactants of metal species. Therefore, in the case of monazite, we suggest to strictly control the temperature and amount of dissolved carbonate species in order to achieve reliable zeta potential comparisons and surface mechanism deduction. Furthermore, this control appears essential to avoid erraticness of zeta potential values that decrease the precision of the IEP calculation.

\section{Acknowledgements}

This research was funded by the Carnot Institutes ICEEL and BRGM through the TERRAFINE Inter-Carnot Action (Carnot-ICEEL no. 118-IC and IC-BRGM no. 2013-01). 
Financial support from LabEx RESSOURCES21 is also acknowledged (contract Investissements d'Avenir no. ANR-10-LABX-0021).

The authors would like to thank Antonin Richard, Jean-Marc Montel and Cecile Fabre for assisting in the preparation and characterisation of the natural monazite sample, and the synthesis of monazite materials. Pierric Hubert is also acknowledged for the XRD analyses.

\section{References}

[1] C.L. Owens, G.R. Nash, K. Hadler, R.S. Fitzpatrick, C.G. Anderson, F. Wall, Zeta potentials of the rare earth element fluorcarbonate minerals focusing on bastnäsite and parisite, Adv. Colloid Interface Sci. 256 (2018) 152-162. doi:10.1016/j.cis.2018.04.009.

[2] R. Houot, J.-P. Cuif, Y. Mottot, J.-C. Samama, Recovery of Rare Earth Minerals, with Emphasis on Flotation Process, Mater. Sci. Forum. 70-72 (1991) 301-324. doi:10.4028/www.scientific.net/MSF.70-72.301.

[3] S.C. Chelgani, M. Rudolph, T. Leistner, J. Gutzmer, U.A. Peuker, A review of rare earth minerals flotation: Monazite and xenotime, Int. J. Min. Sci. Technol. 25 (2015) 877-883. doi:10.1016/j.ijmst.2015.09.002.

[4] T.-W. Cheng, Technical Note - The point of zero charge of monazite and xenotime, Miner. Eng. 13 (2000) 105-109. doi:0892-6875(99)00153-3.

[5] X. Zhang, H. Du, X. Wang, J.D. Miller, Surface chemistry considerations in the flotation of rare-earth and other semisoluble salt minerals, Miner. Metall. Process. 30 (2013) 24-37.

[6] S.B. Balachandran, G. Simkovich, F.F. Aplan, The influence of point defects on the floatability of cassiterite, I. Properties of synthetic and natural cassiterites, Int. J. Miner. Process. 21 (1987) 157-171. doi:10.1016/0301-7516(87)90051-2.

[7] A. Mehdilo, M. Irannajad, B. Rezai, Effect of chemical composition and crystal chemistry on the zeta potential of ilmenite, Colloids Surf. Physicochem. Eng. Asp. 428 (2013) 111119. doi:10.1016/j.colsurfa.2013.03.032.

[8] X.K. Zhu, R.K. O’Nions, Monazite chemical composition: some implications for monazite 
geochronology, Contrib. Mineral. Petrol. 137 (1999) 351-363. doi:10.1007/s004100050555.

[9] N. Clavier, R. Podor, N. Dacheux, Crystal chemistry of the monazite structure, J. Eur. Ceram. Soc. 31 (2011) 941-976. doi:10.1016/j.jeurceramsoc.2010.12.019.

[10] R. Podor, M. Cuney, Experimental study of Th-bearing $\mathrm{LaPO}_{4}\left(780{ }^{\circ} \mathrm{C}, 200 \mathrm{MPa}\right)$; implications for monazite and actinide orthophosphate stability, Am. Mineral. 82 (1997) 765-771. doi:10.2138/am-1997-7-815.

[11] C.M. Gramaccioli, A uranium- and thorium-rich monazite from a south-alpine pegmatite at Piona, Italy, Am. Mineral. 63 (1978) 757-761.

[12] A.-M. Seydoux-Guillaume, R. Wirth, W. Heinrich, J.-M. Montel, Experimental determination of Thorium partitioning between monazite and xenotime using analytical electron microscopy and X-ray diffraction Rietveld analysis, Eur. J. Mineral. 14 (2002) 869-878. doi:10.1127/0935-1221/2002/0014-0869.

[13] J. Nduwa-Mushidi, C.G. Anderson, Surface Chemistry and Flotation Behaviors of Monazite-Apatite-Ilmenite-Quartz-Rutile-Zircon with Octanohydroxamic Acid, J. Sustain. Metall. 3 (2017) 62-72. doi:10.1007/s40831-016-0114-0.

[14] G.S. Was, The Displacement of Atoms, in: Fundam. Radiat. Mater. Sci., Springer New York, New York, NY, 2017: pp. 77-130. doi:10.1007/978-1-4939-3438-6_2.

[15] R. Devanathan, L.R. Corrales, W.J. Weber, A. Chartier, C. Meis, Molecular dynamics simulation of energetic uranium recoil damage in zircon, Mol. Simul. 32 (2006) 1069-1077. doi:10.1080/08927020600959929.

[16] A.-M. Seydoux-Guillaume, R. Wirth, A. Deutsch, U. Schärer, Microstructure of 24-1928 Ma concordant monazites; implications for geochronology and nuclear waste deposits, Geochim. Cosmochim. Acta. 68 (2004) 2517-2527. doi:10.1016/j.gca.2003.10.042.

[17] A.M. Seydoux-Guillaume, R. Wirth, L. Nasdala, M. Gottschalk, J.M. Montel, W. Heinrich, An XRD, TEM and Raman study of experimentally annealed natural monazite, Phys. Chem. Miner. 29 (2002) 240-253. doi:10.1007/s00269-001-0232-4.

[18] A.-M. Seydoux-Guillaume, X. Deschanels, C. Baumier, S. Neumeier, W.J. Weber, S. 
Peuget, Why natural monazite never becomes amorphous: Experimental evidence for alpha self-healing, Am. Mineral. 103 (2018) 824-827. doi:10.2138/am-2018-6447.

[19] J. Kragten, L.G. Decnop-Weever, Hydroxide complexes of lanthanides-VIII: Lanthanum(III) in perchlorate medium, Talanta. 34 (1987) 861-864. doi:10.1016/00399140(87)80115-7.

[20] A. Geneyton, L.O. Filippov, A. Renard, M. Mallet, N.-E. Menad, Advances in carboxylate collector adsorption on monazite surface: Part 1 - Assessment of the hydroxylation and carbonation of surface lanthanide ions, Appl. Surf. Sci. (Under review) (n.d.).

[21] E.R.L. Espiritu, G.R. Da Silva, K.E. Waters, The effect of carbonate ions on the electrokinetic properties of bastnaesite, monazite and xenotime, in: IMPC, Québec, Canada, 2016.

[22] R.F. Weiss, Carbon dioxide in water and seawater: the solubility of a non-ideal gas, Mar. Chem. 2 (1974) 203-215. doi:10.1016/0304-4203(74)90015-2.

[23] H.S. Choi, K.U. Whang, Mechanism of collector adsorption on monazite, J. Korean Chem. Soc. 7 (1963) 91-95.

[24] J. Ren, S. Song, A. Lopez-Valdivieso, S. Lu, Selective flotation of bastnaesite from monazite in rare earth concentrates using potassium alum as depressant, Int. J. Miner. Process. 59 (2000) 237-245. doi:10.1016/S0301-7516(99)00075-7.

[25] J. Luo, C. Xiangyong, Research into the recovery of high-grade rare earth concentrate from Baotou complex iron ore, China, Beijing Mining and Metallurgical Research Institute, 1987.

[26] E.R.L. Espiritu, K.E. Waters, Flotation studies of monazite and dolomite, Miner. Eng. 116 (2018) 101-106. doi:10.1016/j.mineng.2017.02.010.

[27] O. Pavez, P.R.G. Brandao, A.E.C. Peres, Adsorption of oleate and octyl-hydroxamate on to rare-earths minerals, Miner. Eng. 9 (1996) 357-366. doi:10.1016/0892-6875(96)00020-9.

[28] T.-W. Cheng, P.N. Holtham, T. Tran, Froth flotation of monazite and xenotime, Miner. Eng. 6 (1993) 341-351. doi:10.1016/0892-6875(93)90014-E.

[29] W. Zhang, R.Q. Honaker, Flotation of monazite in the presence of calcite part II: Enhanced 
separation performance using sodium silicate and EDTA, Miner. Eng. (2018). doi:10.1016/j.mineng.2018.01.042.

[30] M. Li, K. Gao, D. Zhang, H. Duan, L. Ma, L. Huang, The influence of temperature on rare earth flotation with naphthyl hydroxamic acid, J. Rare Earths. 36 (2018) 99-107. doi:10.1016/j.jre.2017.07.004.

[31] A.M. Abeidu, The separation of monazite from zircon by flotation, J. Common Met. 29 (1972) 113-119. doi:10.1016/0022-5088(72)90181-6.

[32] D. Azizi, F. Larachi, M. Latifi, Ionic-liquid collectors for rare-earth minerals flotation: Case of tetrabutylammonium bis(2-ethylhexyl)-phosphate for monazite and bastnäsite recovery, Colloids Surf. Physicochem. Eng. Asp. $506 \quad$ (2016) 74-86. doi:10.1016/j.colsurfa.2016.06.011.

[33] A. Sarvaramini, D. Azizi, F. Larachi, Hydroxamic acid interactions with solvated cerium hydroxides in the flotation of monazite and bastnäsite-Experiments and DFT study, Appl. Surf. Sci. 387 (2016) 986-995. doi:10.1016/j.apsusc.2016.07.044.

[34] W. Zhang, R. Honaker, Surface charge of rare earth phosphate (monazite) in aqueous solutions, Powder Technol. 318 (2017) 263-271. doi:10.1016/j.powtec.2017.05.048.

[35] W. Zhang, R.Q. Honaker, J.G. Groppo, Flotation of monazite in the presence of calcite part I: Calcium ion effects on the adsorption of hydroxamic acid, Miner. Eng. 100 (2017) 40-48. doi:10.1016/j.mineng.2016.09.020.

[36] G.B. Abaka-Wood, J. Addai-Mensah, W. Skinner, A study of flotation characteristics of monazite, hematite, and quartz using anionic collectors, Int. J. Miner. Process. 158 (2017) 55-62. doi:10.1016/j.minpro.2016.11.012.

[37] E.R.. Espiritu, G.R. da Silva, D. Azizi, F. Larachi, K.E. Waters, The effect of dissolved mineral species on bastnäsite, monazite and dolomite flotation using benzohydroxamate collector, Colloids Surf. Physicochem. Eng. Asp. 539 (2018) 319-334. doi:10.1016/j.colsurfa.2017.12.038.

[38] A. Richard, J.-M. Montel, R. Leborgne, C. Peiffert, M. Cuney, M. Cathelineau, Monazite 
Alteration in $\mathrm{H}_{2} \mathrm{O} \pm \mathrm{HCl} \pm \mathrm{NaCl} \pm \mathrm{CaCl}_{2}$ Fluids at $150{ }^{\circ} \mathrm{C}$ and $\mathrm{p}_{\text {sat: }}$ Implications for Uranium Deposits, Minerals. 5 (2015) 693-706. doi:10.3390/min5040518.

[39] R. Hunter, Zeta Potential in Colloid Science - Principles and Applications, Academic Press, New York, 1981. 